\title{
Micro-rheological changes during experimental acute pancreatitis in the rat
}

4

\author{
Robert Kotan $^{\mathrm{a}}$, Norbert Nemeth ${ }^{\mathrm{b}, *}$, Ferenc Kiss $^{\mathrm{b}}$, Janos Posan ${ }^{\mathrm{a}}$, Kornel Miszti-Blasius ${ }^{\mathrm{c}}$, \\ Laszlo Toth $^{\mathrm{d}}$, Istvan Furka ${ }^{\mathrm{b}}$, Iren Miko ${ }^{\mathrm{b}}$, Peter Sapy ${ }^{\mathrm{a}}$ and Zsolt Szentkereszty ${ }^{\mathrm{a}}$ \\ ${ }^{a}$ Institute of Surgery, Medical and Health Science Center, University of Debrecen, Debrecen, Hungary \\ ${ }^{\mathrm{b}}$ Department of Operative Techniques and Surgical Research, Medical and Health Science Center, \\ University of Debrecen, Debrecen, Hungary \\ ${ }^{\mathrm{c}}$ Department of Clinical Biochemistry and Molecular Pathology, Medical and Health Science Center, \\ University of Debrecen, Debrecen, Hungary \\ ${ }^{\mathrm{d}}$ Department of Pathology, Medical and Health Science Center, University of Debrecen, Debrecen, \\ Hungary
}

Received 1 December 2011

Accepted 3 January 2012

\begin{abstract}
Although microcirculatory disturbances play pivotal role in the pathomechanism of acute pancreatitis (AP), very few papers can be found which had been tested any of hemorheological parameters. The aim of our study was to analyze the hemorheological changes in cerulein-induced experimental acute pancreatitis in rat in two doses $(5 \mathrm{and} 10 \mu \mathrm{g} / \mathrm{kg}$, s.c.). Male and female rats were subjected to Control group, or AP with 5 or $10 \mu \mathrm{g} / \mathrm{kg}$ cerulein groups. Blood samplings (lateral caudal vein) were completed before cerulein administration, and 1,2 and 24 hours later. Hematological parameters, amylase activity, erythrocyte deformability (ektacytometry) and aggregation (light-transmission method) were tested. The presence of AP could be confirmed by amylase testing and histological examination. The earliest impairment of the red blood cell deformability could be observed 1 hour after cerulein administration in $10 \mu \mathrm{g} / \mathrm{kg}$ dosage. Female animals had the worst rheological results with high mortality. In conclusion, subcutaneously administrated cerulein in dosage of 5 and $10 \mu \mathrm{g} / \mathrm{kg}$ resulted in AP in rats, with significant changes in red blood cell deformability and alterations in erythrocyte aggregation. This model seems to be suitable for further comparative studies.
\end{abstract}

Keywords: Red blood cell deformability, red blood cell aggregation, acute pancreatitis, rat model, cerulein induced-pancreatitis

\section{Introduction}

Acute pancreatitis still means an important clinical problem. In the latest decades its mortality has not been changed significantly, furthermore, the pathomechamism is still not completely clarified, yet. There are three main theories of pathophysiological pathways of severe acute pancreatitis: (1) pancreatic autodigestion, (2) leukocyte activation induced by activation the inflammatory mediators and/or cytokines and (3) pancreatic microcirculatory disturbances $[6,11,16,27,32,35]$.

\footnotetext{
${ }^{*}$ Corresponding author: Norbert Nemeth, M.D., Ph.D., Department of Operative Techniques and Surgical Research, Institute of Surgery, Medical and Health Science Center, University of Debrecen, Nagyerdei krt. 98., H-4032 Debrecen, Hungary. Tel.: +36 52416 915; E-mail: nemeth@med.unideb.hu.
} 
One of the most important causes in the development of severe acute pancreatitis is the disturbance of the pancreatic microcirculation. Many cytokines and mediators, such as nitric oxide, reactive oxygen free radicals, platelet activation factor, adhesion molecules, endothelin-1, tumor necrosis factor- $\alpha$, thromboxans, bradykinine and prostaglandins play determinative role $[9,17,27,35]$.

It is also well known that blood micro-rheological properties are the major determinants of tissue microcirculation [18-20, 26]. Impaired red blood cell deformability and enhanced aggregation may contribute to microcirculatory disturbances $[1,19,20,26]$. However, there is a lack of hemorheological data in acute pancreatitis: very little number of clinical and experimental papers can be found in the literate, in which any of hemorheological parameters had been measured [5, 8]. Though, there are only some studies about the hemorheological-microcirculatory changes in experimental acute pancreatitis [23, $35,37]$.

For investigation of pathomechanisms and prevention as well as therapeutic possibilities of acute pancreatitis, several non-invasive and invasive experimental models are known. Non-invasive methods include hormones and chemicals (cerulein, Trinidadian scorpion toxin, anti-cholinesterase insecticide), ethyl-alcohol, various nutrients and oils, L-arginine, immune-mediated and gene knock-out models. Invasive methods are aiming obstruction of pancreatic ducts, performing arterial or venous vascular occlusion, causing ischemia-reperfusion, microcirculatory disturbances or causing traumatization of the pancreas tissue [14, 21, 28-31, 33, 36, 38].

The cerulein-induced acute pancreatitis model is simple to be performed, being non-invasive. However, we could not find data in the literature about experimental acute pancreatitis induced by various dosage of cerulein, in which study red blood cell deformability or red blood cell aggregation data would have been presented.

The aim of this preliminary study was to analyze the hemorheological changes in cerulein-induced experimental acute pancreatitis in rat in two doses ( 5 and $10 \mu \mathrm{g} / \mathrm{kg}$, s.c.), and also aiming to analyze the possible gender difference in hemorheological response.

\section{Materials and methods}

\subsection{Experimental animals and groups}

The experiments were approved and registered by the University of Debrecen Committee of Animal Research (permission Nr.: 16/2008), in accordance with the relevant Hungarian Animal Protection Act (Law XVIII/1998) and EU Directives (EEC 63/2010).

Fourteen male $(595.7 \pm 39.2 \mathrm{~g})$ and twelve female (344.6 $\pm 52.5 \mathrm{~g})$ Sprague-Dawley rats (Janvier Co., France) were randomly involved into the following experimental groups:

I. Control ( $n=8 ; 4$ males and 4 females)

II. Acute Pancreatitis with $5 \mu \mathrm{g} / \mathrm{kg}$ cerulein (AP-5, $n=10 ; 5$ males and 5 females)

III. Acute Pancreatitis with $10 \mu \mathrm{g} / \mathrm{kg}$ cerulein (AP-10, $n=8 ; 5$ males and 3 females).

All animals were anesthetized using $60 \mathrm{mg} / \mathrm{kg}$, Thiopenthal ${ }^{\circledR}$ intraperitoenally. For inducing acute pancreatitis, cerulein (Sigma-Aldrich Co., Budapest) was used subcutaneously (right abdominal region) in $5 \mu \mathrm{g} / \mathrm{kg}$ or $10 \mu \mathrm{g} / \mathrm{kg}$ dose, dissolved in sterile physiological saline solution. In Control group the 
same-volume sterile physiological saline solution was given subcutaneously. After the blood samplings at 2 hours, Flunixin ${ }^{\circledR}$ was administrated to each animal $(2.5 \mathrm{mg} / \mathrm{kg}$, s.c.) for analgesia.

Before cerulein administration, 1, 2 and 24 hours after it (in re-anesthesia) $0.6-0.8 \mathrm{ml}$ blood was taken from the lateral caudal vein (24-26 G needle; anticoagulant: sodium-EDTA, $1.5 \mathrm{mg} / \mathrm{ml}$ ). In anesthesia, after the last blood sampling median laparotomy and thoracotomy was performed for taking biopsies from the pancreas, small intestine, liver, kidney and lung.

\subsection{Laboratory investigations}

For determining general quantitative and qualitative hematological parameters a Sysmex F-800 microcell counter was used (TOA Medical Electronics Co., Japan).

Red blood cell deformability was tested by a Rheoscan-D200 ektacytometer (Sewon Meditech Inc., Korea) [15]. Suspension of native blood $(6 \mu \mathrm{l})$ and ; $\mathrm{pH}=7.36)$ was taken into Rheoscan disposable slit-flow kit. At the beginning of the test the device is generating vacuum, resulting in a rapid flow, then a continuously decreasing flow rate in the micro-channel. The created shear stress range of $\sim$ 0.5 - $20 \mathrm{~Pa}$ provide elongation of red blood cells, altering the laser diffraction pattern. The elongation index (EI) at a constant shear stress (SS [Pa]) is calculated from the length (L) and width (W) of the diffractoisotonic solution of polyvinylpyrrolidone $(0.6 \mathrm{ml})$ (PVP; $360 \mathrm{kDa}$, viscosity $=30 \mathrm{mPa} . \mathrm{s}$; osmolarity $=305 \mathrm{mOsm} / \mathrm{kggram}: \mathrm{EI}=(\mathrm{L}-\mathrm{W}) /(\mathrm{L}+\mathrm{W})$. EI increases with cell deformability $[2,15]$. For comparison EI values at $3 \mathrm{~Pa}$ were used and parameterization of individual curves Lineweaver-Burke analysis was completed in a range of 1-20 Pa shear stress: maximal elongation index $\left(\mathrm{EI}_{\max }\right)$ and the shear stress at half $\mathrm{EI}_{\max }\left(\mathrm{SS}_{1 / 2}[\mathrm{~Pa}]\right)$ were calculated [4].

Red blood cell aggregation was tested by light-transmission method, using a Myrenne MA-1 erythrocyte aggregometer (Myrenne GmbH, Germany). M (at 0 shear rate) and M1 (at shear rate of $3 \mathrm{~s}^{-1}$ ) indices were measured at the 5 th or 10th seconds of the aggregation process $[2,14]$. The measurements were carried out within 1 hour after sampling [24].

Since the blood sampling volume was limited in the rat, the anticoagulated blood samples were centrifuged and the plasma was used for the enzyme activity examination (values being 5-10\% lower compared to serum). Plasma $\alpha$-amylase activity [U/l] was determined by a clinical chemistry automate COBAS Integra, using enzymatic colorimetrical method (Roche Diagnostics GmbH, Germany).

\subsection{Histological examinations}

Tissue samples were fixed in $4 \%$ buffered formaldehyde solution, dehydrated in a graded series of alcohol, embedded in paraffin. The blocks were microtomed into 3-5 $\mu \mathrm{m}$ step sections and stained with hematoxylin and eosin (H\&E).

\subsection{Statistical analyses}

Data are presented as mean \pm standard deviation (S.D.). According to the data distribution, Student $t$-test or Mann-Whitney RS test was used for inter-group comparison, and one-way ANOVA tests (Dunn's or Bonferroni's method) were performed to evaluate the changes within groups (e.g. base $-1 \mathrm{~h}-2 \mathrm{~h}-24 \mathrm{~h}$ data). A $p$ value less than 0.05 was considered as statistically significant. 


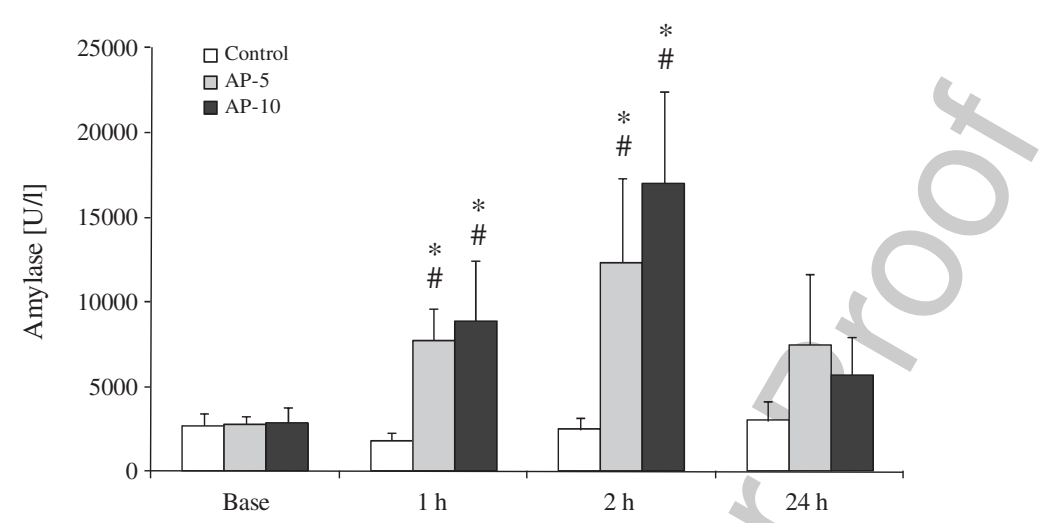

Fig. 1. Changes of amylase activity [U/l] in Control and Acute Pancreatitis groups of 5 or $10 \mu \mathrm{g} / \mathrm{kg}$ cerulein (AP-5, AP-10) prior to and 1, 2 and 24 hours after the administration of cerulein. means \pm S.D., $* p<0.05$ vs. base, ${ }^{*}$ Control

\section{Results}

\subsection{Survival}

There was no death in Control. All male animals of AP-5 and PA-10 groups survived till the 24th hour. In AP-5 group 2 of 5 females died by 24 hours. In AP- 10 group one female animal exited within 1.5 hour after cerulein administration, the resting 2 females died by the morning of the next day.

\subsection{Changes of amylase activity and histological observation}

Both amylase testing and histological examinations of pancreas (data not shown) confirmed the presence of acute pancreatitis both in AP-5 and AP-10 groups.

Figure 1 shows the changes of amylase enzyme activity. In both acute pancreatitis groups amylase activity significantly rose 1 hour after administration of cerulein and continued to increase by 2 hours. The elevation of enzyme activity was more expressed in AP-10 group. The rise in amylase activity was significant in both AP groups versus their base (AP-5: $p=0.023$ at $1 \mathrm{~h}$ and $p<0.001$ at $2 \mathrm{~h}$; AP-10: $p=0.011$ at $1 \mathrm{~h}$ and $p<0.001$ at $2 \mathrm{~h}$ ) or compared to Control (AP-5: $p=0.001$ at $1 \mathrm{~h}$ and $p<0.001$ at $2 \mathrm{~h}$; AP-10: $p=0.001$ at $1 \mathrm{~h}$ and $p=0.003$ at $2 \mathrm{~h}$ ). There was no remarkable gender difference in the magnitude of amylase activity increasing. In survivor animals the amylase activity decreased by the 24th hour, being elevated compared to control animals.

\subsection{Changes of hematological parameters}

Leukocyte count (WBC $\left[\times 10^{3} / \mu 1\right]$ ) tended to decrease 1 or 2 hours after cerulein administration (just significantly in AP-5 group: $p=0.049$ at $1 \mathrm{~h}, p=0.047$ at $2 \mathrm{~h}$ versus base). By 24 hours the values increased $(p=0.012$ vs. base), but being more expressed in AP-10 group ( $p<0.001$ vs. base, $p=0.004$ vs. Control, $p<0.001$ vs. AP-5) (Fig. 2A).

Red blood cell count $\left(\mathrm{RBC}\left[\times 10^{6} / \mu \mathrm{l}\right]\right)$ together with the hematocrit $(\mathrm{Hct}[\%])$ showed slightly elevated values in both AP groups compared to Controls, reaching significantly higher values by 24 hours: in AP- 5 group RBC $p=0.02$ vs. base and $p=0.026$ vs. Control; Hct $p=0.008$ vs. base ( $p=0.059$ vs. Control); 

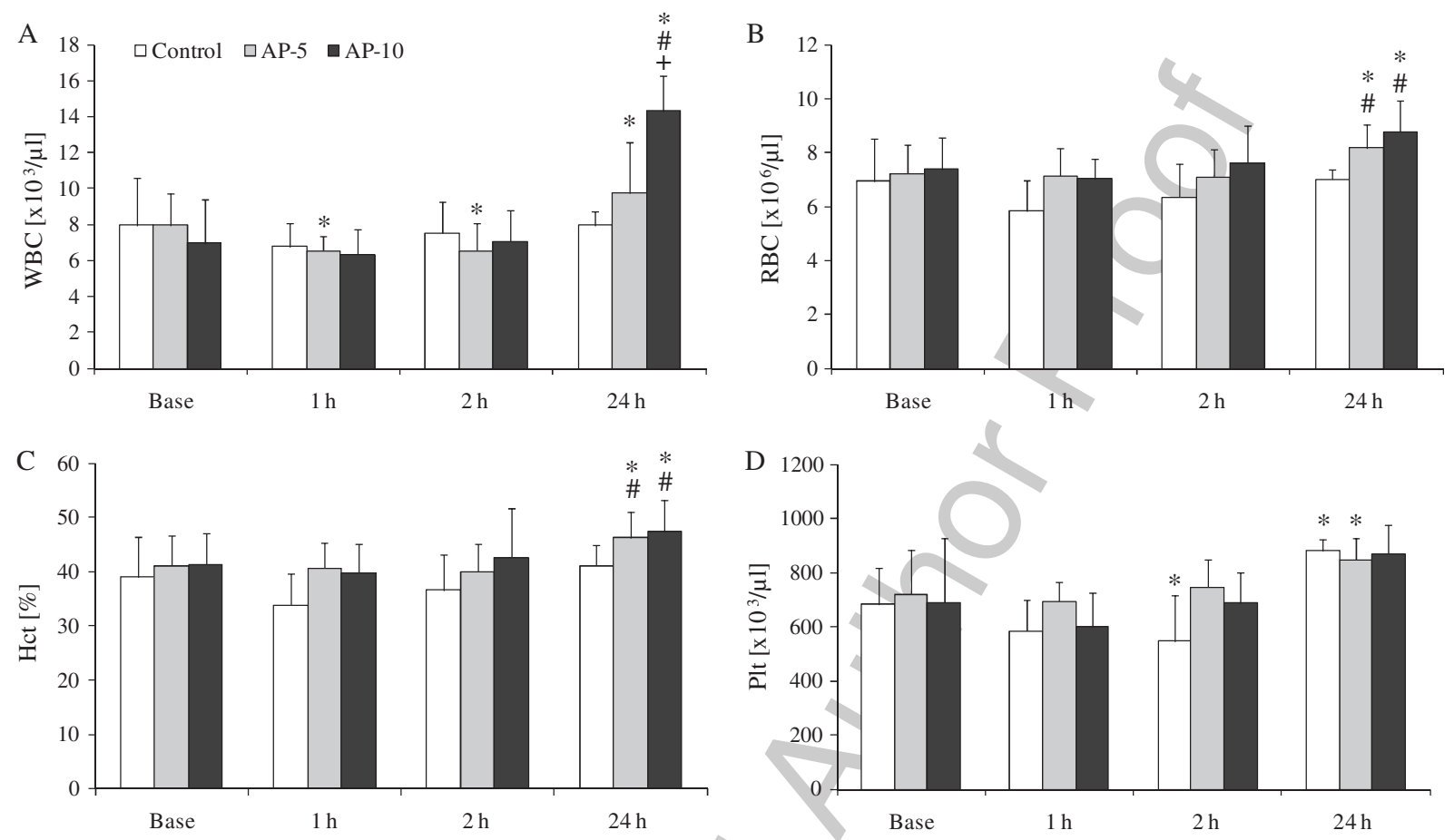

Fig. 2. Changes of white blood cell count $\left(\operatorname{WBC}\left[\times 10^{3} / \mu 1\right]\right)(\mathrm{A})$, red blood cell count $\left(\mathrm{RBC}\left[\times 10^{6} / \mu \mathrm{l}\right]\right)(\mathrm{B})$, hematocrit $(\mathrm{Hct}$ $[\%])(\mathrm{C})$ and platelet count $\left(\mathrm{Plt}\left[\times 10^{3} / \mu \mathrm{l}\right]\right)(\mathrm{D})$ in Control and Acute Pancreatitis groups of 5 or $10 \mu \mathrm{g} / \mathrm{kg}$ cerulein (AP-5, AP-10) prior to and 1, 2 and 24 hours after the administration of cerulein. means \pm S.D., ${ }^{*} p<0.05$ vs. base, ${ }^{\#}$ Control; + vs. AP-5

and in AP-10 group RBC $p=0.021$ vs. base and $p=0.017$ vs. Control; Hct $p=0.028$ vs. base and $p 0.048$ vs. Control (Fig. 2B, C).

After a mild decrease over the first 2 hours, platelet count $\left(\mathrm{Plt}\left[\times 10^{3} / \mu \mathrm{l}\right]\right)$ showed moderate increase by 24 hours in all groups. The increase reached significant level in Control and in AP-5 groups $(p=0.044$ and $p=0.005$ vs. base, respectively) (Fig. 2D).

\subsection{Changes of red blood cell deformability}

Table 1 shows elongation index (EI) values at shear stress of $3 \mathrm{~Pa}$, as well as calculated maximal elongation index $\left(\mathrm{EI}_{\max }\right)$ and shear stress of half-EI $\mathrm{I}_{\max }\left(\mathrm{SS}_{1 / 2}[\mathrm{~Pa}]\right)$.

The EI-SS curves became distorted over $5 \mathrm{~Pa}$ in AP-5 and AP-10 groups. Therefore, the calculated values $\left(\mathrm{EI}_{\max }\right.$ and $\left.\mathrm{SS}_{1 / 2}\right)$ were also influenced by the irregular curve shape.

In Control animals EI at 3 Pa slightly decreased at 1 and 2 hours, and by 24 hours moderately increased, which changes were reflected by the calculated $\mathrm{EI}_{\max }$ and $\mathrm{SS}_{1 / 2}$ values.

In AP-5 group the EI values rather increased, resulting in significant difference versus base values on the next day $(p<0.001)$. It was not seen in $\mathrm{EI}_{\max }$ data, while the $\mathrm{SS}_{1 / 2}$ values significantly decreased by 24 hours ( $p=0.006$ vs. base).

In AP-10 group the EI values at 3 Pa significantly worsened 1 hour ( $p=0.002$ vs. base) and 2 hours $(p=0.022$ vs. base) after cerulein administration. By the 24 th hour EI values normalized in survivor 
Table 1

Changes of selected comparative parameters of elongation index (EI) - shear stress (SS) curves in the experimental groups

\begin{tabular}{lccccc}
\hline Variable & Group & \multicolumn{1}{c}{ Base } & \multicolumn{1}{c}{$1 \mathrm{~h}$} & $2 \mathrm{~h}$ & $24 \mathrm{~h}$ \\
\hline EI at $3 \mathrm{~Pa}$ & Control & $0.342 \pm 0.013$ & $0.335 \pm 0.012$ & $0.334 \pm 0.01$ & $0.353 \pm 0.019$ \\
& AP-5 & $0.337 \pm 0.011$ & $0.341 \pm 0.01$ & $0.343 \pm 0.01^{\#}$ & $0.363 \pm 0.014^{*}$ \\
& AP-10 & $0.347 \pm 0.001$ & $0.332 \pm 0.016^{*}$ & $0.324 \pm 0.033^{*}$ & $0.354 \pm 0.011$ \\
& & & & & \\
$\mathrm{EI}_{\max }$ & Control & $0.587 \pm 0.015$ & $0.600 \pm 0.037$ & $0.592 \pm 0.027$ & $0.605 \pm 0.024$ \\
& AP-5 & $0.593 \pm 0.019$ & $0.599 \pm 0.017$ & $0.593 \pm 0.02$ & $0.587 \pm 0.024$ \\
& AP-10 & $0.584 \pm 0.015$ & $0.588 \pm 0.012$ & $0.608 \pm 0.046^{*}$ & $0.588 \pm 0.011$ \\
$\mathrm{SS}_{1 / 2}[\mathrm{~Pa}]$ & Control & $2.39 \pm 0.33$ & $2.68 \pm 0.67$ & $2.6 \pm 0.38$ & $2.43 \pm 0.54$ \\
& AP-5 & $2.52 \pm 0.32$ & $2.54 \pm 0.31$ & $2.44 \pm 0.34$ & $2.14 \pm 0.39^{*}$ \\
& AP-10 & $2.31 \pm 0.27$ & $2.57 \pm 0.45$ & $3.14 \pm 1.55 *$ & $2.21 \pm 0.16$ \\
\hline
\end{tabular}

means \pm S.D. EI at $3 \mathrm{~Pa}=$ elongation index at shear stress of $3 \mathrm{~Pa} ; \mathrm{EI}_{\max }=$ calculated maximal elongation index; $\mathrm{SS}_{1 / 2}=$ shear stress values at half maximal elongation index. ${ }^{*} p<0.05$ vs. base; ${ }^{*}$ vs. Control.

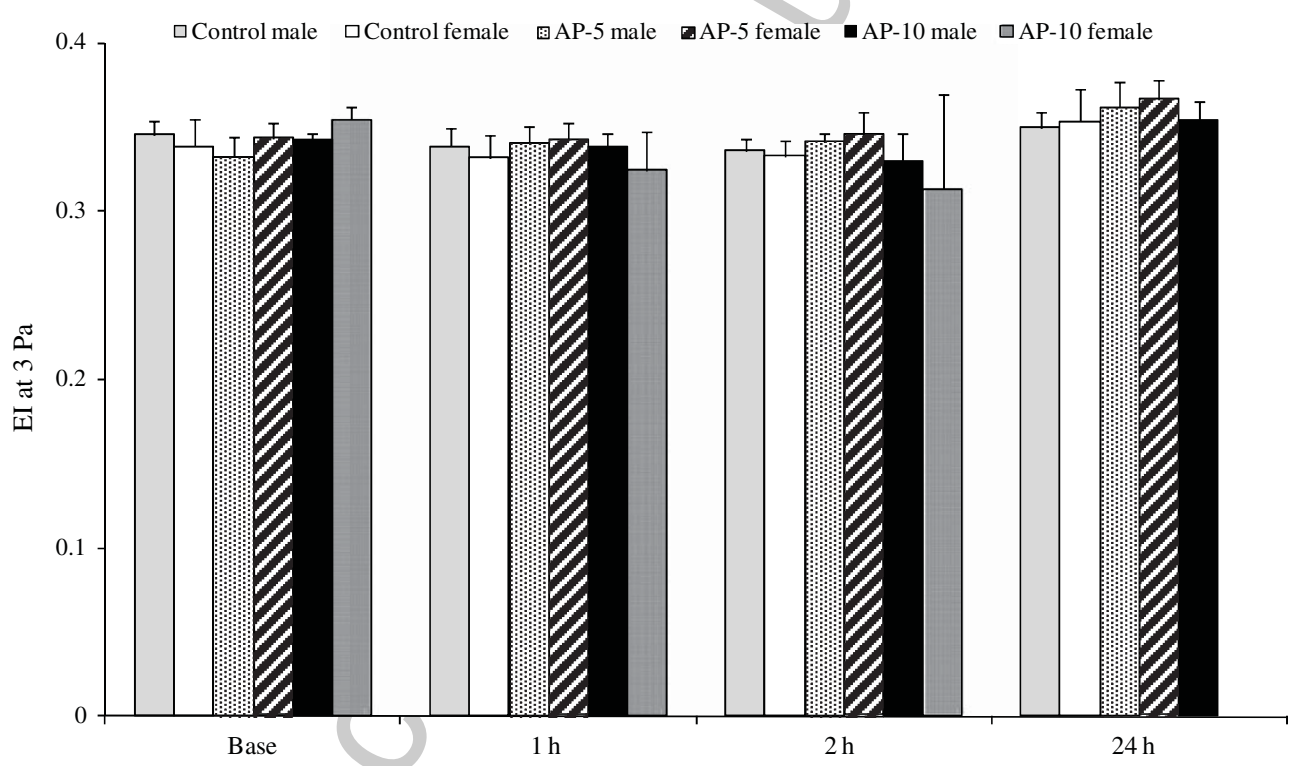

Fig. 3. Changes of elongation index values at shear stress of $3 \mathrm{~Pa}$ in male and female animals of Control and Acute Pancreatitis groups of 5 or $10 \mu \mathrm{g} / \mathrm{kg}$ cerulein (AP-5, AP-10) prior to and 1, 2 and 24 hours after the administration of cerulein.

animals. Supposedly because of the distorted EI-SS curves, the calculated $\mathrm{EI}_{\max }$ values increased at 2 hours. $\mathrm{SS}_{1 / 2}$ values increased by 1 hour ( $p=0.061$ vs. base) and 2 hours ( $p=0.033$ vs. base).

We analyzed the data in respect of the genders. Figure 3 shows EI at $3 \mathrm{~Pa}$ values in male and female animals. It seemed that the decrease in EI values of AP-10 group was more expressed in female animals, however, the standard deviation increased in data at 2 hours (Fig. 3). 


\subsection{Alteration in red blood cell aggregation}

Aggregation index values were tested but with oncoming difficulties. There were numerous samples, in which the measured values were zero; therefore, we could not evaluate the groups' data convincingly. What we could see was a general increase in aggregation index values by 2 hours and 24 hours in AP-5 and AP-10 groups. Because of the numerous not valuable tests (measured values: 0), statistical analyses could not be performed.

\section{Discussion}

To investigate severe acute pancreatitis numerous animal models (non-invasive or invasive) have been carried out [14, 28-31]. The advantages of the invasive models are their reproducibility, usefulness for studying obstruction-, vascular and reflux-induced pancreatitis. Their disadvantages are the need of bigger animals, expensiveness, and technical difficulties. The cheapness and the simplicity are the advantages of non-invasive models. One of the most often used non-invasive models is the cerulein-induced model. It can be used successfully in dogs, rats, Syrian hamsters and mice [31].

Cerulein is a cholecystokinin-pancreozymin analogue. By its usage proteolytic enzyme secretion increases, causing pancreatic acinar autolysis, even 1 hour after administration. In rat model the changes in acinar cells (intracellular membrane system) and pulmonary consequences may resemble the human acute pancreatitis $[14,31,33,36]$. However, the severity of the induced pancreatitis may vary, depending on the dosage, way of administration (subcutaneous, intravenous, intraperitoneal), showing individual variations as well as inter-species differences $[31,33]$.

There are high varieties reported about the dosage of cerulein [10,31]. Clemons et al. used $10 \mu \mathrm{g} / \mathrm{kg}$ s.c. dose and $5 \mu \mathrm{g} / \mathrm{kg}$ s.c. hourly for 5 hours in rats. They found significant increase in pancreatic weight, serum amylase activity [10]. Early studies used high dose, even $50 \mu \mathrm{g} / \mathrm{kg}[10,38]$. In our study we aimed to investigate a relatively low dose protocol of 5 and $10 \mu \mathrm{g} / \mathrm{kg}$ cerulein, given subcutaneously. We aimed to investigate whether these doses induce acute pancreatitis with measurable hemorheological changes.

We found micro-rheological changes in cerulein-induced acute pancreatitis, showing further differences depending on the cerulein dosage and gender. The presence of acute pancreatitis could be confirmed by amylase measurements and histological examinations. Hematological parameters showed general inflammatory changes, increase in leukocytes and platelets by 24 hours accompanied by slight hemoconcentration.

Acute pancreatitis is characterized by hyperamylasemia, interstitial edema, pancreas acinar cell swelling, increased pancreatic weight, vacuolization, exacerbation of inflammatory processes $[6,12$, 14, 16]. The disturbances of the pancreas microcirculation can be associated with changing of blood viscosity and impaired red blood cell deformability and enhanced aggregation $[1,20,26]$.

The worsening red blood cell deformability can be caused by the deliberating oxygen delivered free radicals, which play pivotal role in cell and tissue damage [1, 3, 9]. Free radicals may jeopardize the red blood cells by different way: on red cell membrane and proteins (lipid peroxidation, cross-linking in protein sulfhydril groups), as well as in hemoglobin (methemoglobin, Heinz-body formation). Erythrocytes are known to be very sensitive against free radical attack, because they contain much iron (Fenton-reaction) and they have no nucleus, thus, there is no turn-over of damaged cell structure $[1,13]$.

Berezina et al. also found significant decrease of erythrocyte elongation index values in their rat model. The impaired red blood cell deformability could be partially prevented by mesenteric lymph duct 
ligation, suggesting that mesenteric lymph may contains factors that cause those cell damages (activated leukocytes?) [5].

During the inflammatory processes the effect of vasodilatator nitric oxide (NO) cannot be neglected. In the pancreas neurons in intrapancreatic ganglia, intra- and extrapancreatic nerve endings and vascular endothelium are the sources of constitutive NO generation [9, 22]. It was demonstrated that NO may improve red blood cell deformability [1,7]. This could be a reason for the moderate EI increasing in AP-5 groups. Supposedly, the higher dose cerulein could cause more serious damage and consequently more extended inflammation, where the harmful factors became determinative, resulting in significantly decreased red blood cell deformability in AP-10 groups.

The gender differences in hemorheological response for acute pancreatitis were also observed. Previously it was demonstrated that healthy rats show significant gender differences in hemorheological parameters [25]. Male rats have lower red blood cell aggregation index values, but with worse deformability parameters (lower EI values) compared to females. When evaluating the results of this current study, the mortality amongst female animals is not negligible. Although, the case number of this preliminary study was low, it is suggested that hemorheological consequences of acute pancreatitis may be more severe in female rats. This question has to be further investigated, with increased case number and with more sophisticated hemorheological methods.

In addition, the real background of the magnitude of changes is still unclear. In both AP groups the rise in amylase activity was large, histological confirmed acute pancreatitis. However, the red blood cell deformability changes were the most expressed in AP-10 group. The changes in red blood cell aggregation could not be safely evaluated in our current study. Windberger et al. also found that in rat blood the erythrocyte aggregation values are very low and often undetectable by light transmission aggregometry [34]. Furthermore, in Control animals the general effects of the anesthesia and blood samplings have to be taken into consideration, too. These findings, promising results and limitations together with the open questions require further studies.

\section{Conclusion}

Subcutaneously administrated cerulein in dosage of 5 and $10 \mu \mathrm{g} / \mathrm{kg}$ resulted in acute pancreatitis in rats, with significant changes in red blood cell deformability and alterations in red blood cell aggregation. The earliest impairment of the red blood cell deformability could be observed 1 hour after cerulein administration in $10 \mu \mathrm{g} / \mathrm{kg}$ dosage. Female animals had the worst rheological results, and the mortality was the highest among them.

The background of the micro-rheological changes during acute pancreatitis is still controversial in the literature and not clarified, yet. Further studies are needed to explore better the pathophysiological mechanism, the factors influencing the magnitude of changes, together with evaluation of effective microcirculatory therapeutic agents. For these studies the presented model using $10 \mu \mathrm{g} / \mathrm{kg}$ cerulein in female rats seems to be suitable.

\section{Acknowledgments}

Authors are grateful to the technical and laboratory staff of the Department of Operative Techniques and Surgical Research at University of Debrecen. 
Scientific Grants: Hungarian Ministry of Health, Medical Research Council (grant Nr.: ETT 33102/2009.; Z. Szentkereszty); Janos Bolyai Research Scholarship of the Hungarian Academy of Sciences (2010-2013; N. Nemeth).

The authors comply with the Ethical Guidelines for Publication in Clinical Hemorheology and Microcirculation as published on the IOS Press website and in Volume 44, 2010, pp. 1-2 of this journal.

\section{References}

[1] O.K. Baskurt, Mechanisms of blood rheology alterations, in: Handbook of Hemorheology and Hemodynamics, O.K. Baskurt, M.R. Hardeman, M.W. Rampling and H.J. Meiselman, eds, IOS Press, Amsterdam, The Netherlands, 2007, pp. 170-190.

[2] O.K. Baskurt, M. Boynard, G.C. Cokelet, P. Connes, B.M. Cooke, S. Forconi, M.R. Hardeman, F. Jung, F. Liao, H.J. Meiselman, G. Nash, N. Nemeth, B. Neu, B. Sandhagen, S. Shin, G. Thurston and J.L. Wautier, International Expert Panel for Standardization of Hemorheological Methods, New guidelines for hemorheological laboratory techniques, Clin Hemorheol Microcirc 42 (2009), 75-97.

[3] O.K. Baskurt, D. Gelmont and H.J. Meiselman, Red blood cell deformability in sepsis, Am J Respir Crit Care Med 157 (1998), 421-427.

[4] O.K. Baskurt, M.R. Hardeman, M. Uyuklu, P. Ulker, M. Cengiz, N. Nemeth, S. Shin, T. Alexy and H.J. Meiselman, Parameterization of red blood cell elongation index - shear stress curves obtained by ektacytometry, Scan J Clin Lab Inv 69 (2009), 777-788.

[5] T.L. Berezina, S.B. Zaets, D.J. Mole, Z. Spolarics, E.A. Deitch and G.W. Machiedo, Mesenteric duct ligation decreases red blood cell alterations caused by acute pancreatitis, Am J Surg 190 (2005), 800-804.

[6] M. Bhatia, F.L. Wong, Y. Cao, H.Y. Lau, J. Huang, P. Puneet and L. Chevali, Pathophysiology of acute pancreatitis, Pancreatology 5 (2005), 132-144.

[7] M. Bor-Kucukatay, R.B. Wenby, H.J. Meiselman and O.K. Baskurt, Effects of nitric oxide on red blood cell deformability, Am J Physiol Herat Circ Physiol 284 (2003), H1577-H1584.

[8] B. Chmiel, R. Grabowska Bochenek, D. Piskorska, A. Skorupa, L. Cierpka and S. Kusmierski, Red blood cells deformability and oxidative stress in acute pancreatitis, Clin Hemorheol Microcirc 27 (2002), 155-162.

[9] M. Chvanov, O.H. Petersen and A. Tepikin, Free radicals and the pancreatic acinar cells: Role in physiology and pathology, Phil Trans R Soc B 360 (2005), 2273-2284.

[10] A.P. Clemons, D.M. Holstein, A. Galli and C. Saunders, Cerulein-induced acute pancreatitis in the rat is significantly ameliorated by treatment with MEK1/2 inhibitors U0126 and PD98059, Pancreas 25 (2002), 251-259.

[11] L.I. Cosen-Binker and H.Y. Gaisano, Recent insights into the cellular mechanisms of acute pancreatitis, Can J Gastroenterol 21 (2007), 19-24.

[12] A.C. de Beaux, A.S. Goldie, J.A. Ross, D.C. Carter and K.C. Fearon, Serum concentrations of inflammatory mediators related to organ failure in patients with acute pancreatitis, Br J Surg 83 (1996), 349-353.

[13] S. de Oliveira and C. Saldanha, An overview about erythrocyte membrane, Clin Hemorheol Microcirc 44 (2010), 63-74.

[14] J. Granger and D. Remick, Acute pancreatitis: Models, markers, and mediators, Shock 24(Suppl 1) (2005), 45-51.

[15] M.R. Hardeman, P.T. Goedhart and S. Shin, Methods in hemorheology, in: Handbook of Hemorheology and Hemodynamics, O.K. Baskurt, M.R. Hardeman, M.W. Rampling and H.J. Meiselman, eds., IOS Press, Amsterdam, The Netherlands, 2007, pp. 242-266.

[16] S.J. Harper and S. Cheslyn-Curtis, Acute pancreatitis, Ann Clin Biochem 48 (2011), 23-37.

[17] A.T. Isik, M.R. Mas, L. Yamanel, S. Aydin, B. Comert, C. Akay, G. Erdem and N. Mas, The role of allopurinol in experimental acute necrotizing pancreatitis, Indian J Med Res 124 (2006), 709-714.

[18] F. Jung, From hemorheology to microcirculation and regenerative medicine: Fåhraeus Lecture 2009, Clin Hemorheol Microcirc 45 (2010), 79-99.

[19] F. Jung, C. Mrowietz, B. Hiebl, R.P. Franke, G. Pindur and R. Sternitzky, Influence of rheological parameters on the velocity of erythrocytes passing nailfold capillaries in humans, Clin Hemorheol Microcirc 48 (2011), 129-139. 
[20] E. Kaliviotis, I. Ivanov, N. Antonova and M. Yianneskis, Erythrocyte aggregation at non-steady flow conditions: A comparison of characteristics measured with electrorheology and image analysis, Clin Hemorheol Microcirc 44 (2010), 43-54.

[21] L. Kerekes, P. Arkossy, I. Altorjay, M. Huszka, J. Kappelmayer, P. Toth, Z. Szentkereszty and P. Sapy, Evaluation of hemostatic changes and blood antioxidant capacity in acute and chronic pancreatitis, Hepatogastroenterol 48 (2001), 1746-1749.

[22] A.L. Kirchgessner, M.T. Liu and M.D. Gershon, NADPH diaphorase (nitric oxide synthase)-containing nerves in the enteropancreatic innervation: Sources, costored neuropeptides, and pancreatic function, J Comp Neurol 342 (1994), $115-130$.

[23] O. Mann, J. Kaifi, C. Bloechle, C.G. Schneider, E. Yekebas, D. Kluth, J.R. Izbicki and T. Strate, Therapeutic small-volume resuscitation preserves pancreas microcirculation in acute experimental pancreatitis of grad severity in rats, Pancreatology 9 (2009), 652-661.

[24] N. Nemeth, O.K. Baskurt, H.J. Meiselman, F. Kiss, M. Uyuklu, T. Hever, E. Sajtos, P. Kenyeres, K. Toth, I. Furka and I. Miko, Storage of laboratory animal blood samples causes hemorheological alterations: Inter-species differences and the effects of duration and temperature, Korea-Aust Rheol J 21 (2009), 127-133.

[25] N. Nemeth, F. Kiss, I. Furka and I. Miko, Gender differences of blood rheological parameters in laboratory animals, Clin Hemorheol Microcirc 45 (2010), 263-272.

[26] A.S. Popel and P.C. Johnson, Microcirculation hemorheology, Ann Rev Fluid Mech 37 (2005), 43-69.

[27] R.P. Sah and A. Saluja, Molecular mechanisms of pancreatic injury, Curr Opin Gastroenterol 27 (2011), 444-451.

[28] P. Sapy, I. Furka, E. Fabian, I. Miko and G. Balazs, Experimental study of parenteral nutrition and of the exocrine function of the pancreas, Acta Chir Hung 31 (1990), 145-150.

[29] P. Sapy, I. Gal, I. Miko and I. Furka, [Pressure conditions in the pancreatic duct in acute experimental pancreatitis], Acta Chir Acad Sci Hung 22 (1981), 9-13, German.

[30] S. Sipka, P. Sapy, G. Bot, I. Furka, I. Miko, P. Arkossy, G. Dauda, M. Szappanos, J. Kovacs, G. Lakos and G. Szegedi, Protecting effects of intravenous insoluble glycogen treatment on the experimental necrotizing acute pancreatitis of dogs, Hepatogastroenterol 44 (1997), 127-132.

[31] K.H. Su, C. Cuthbertson and C. Christophi, Review of experimental animal models of acute pancreatitis, HPB 8 (2006), 264-286.

[32] Z. Szentkereszty, R. Kotan, J. Posan, P. Arkossy and P. Sapy, Therapeutic tactics in the treatment of acute necrotizing pancreatitis, Hepatogastroenterol 55 (2008), 1172-1174.

[33] L.P. van Minnen, M. Blom, H.M. Timmerman, M.R. Visser, H.G. Gooszen and L.M.A. Akkermans, The use of animal models to study bacterial translocation during acute pancreatitis, J Gastrointest Surg 11 (2007), 682-689.

[34] U. Windberger, A. Bartholovitsch, R. Plasenzotti, K.J. Korak and G. Heinze, Whole blood viscosity, plasma viscosity and erythrocyte aggregation in nine mammalian species: Reference values and comparison of data, Exp Physiol 88 (2003), $431-440$.

[35] X.P. Zhang, Z.J. Li and J. Zhang, Inflammatory mediators and microcirculatory disturbance in acute pancreatitis, Hepatobil Pancreat Dis Int 8 (2009), 351-357.

[36] X.P. Zhang, Q. Ye, X.G. Jiang, M.L. Ma, F.B. Zhu, R.P. Zhang and Q.H. Cheng, Preparation method of an ideal model of multiple organ injury of rat with severe acute pancreatitis, World J Gastroenterol 13 (2007), 4566-4573.

[37] X. Zhang, H. Tian, C. Wu, Q. Ye, X. Jiang, L. Chen, Y. Cai, R. Xu and W. Yuan, Effect of baicalin on inflammatory mediator levels and microcirculation disturbance in rats with severe acute pancreatitis, Pancreas 38 (2009), 732-738.

[38] W. Zhou, B.A. Levine and M.S. Olson, Platelet-activating factor: A mediator of pancreatic inflammation during cerulein hyperstimulation, Am J Pathol 142 (1993), 1504-1512. 